\title{
From the Editors' Desk: The Science and Politics of Screening
}

\author{
Richard L. Kravitz, MD, MSPH' and Mitchell D. Feldman, MD, MPhil \\ 'UC Davis Division of General Medicine, Sacramento, CA, USA; ${ }^{2}$ UC San Francisco Division of General Internal Medicine, San Francisco, CA, USA.
}

$J$ Gen Intern Med 25(2):99

DOI: $10.1007 / \mathrm{s} 11606-009-1222-3$

(c) Society of General Internal Medicine 2010

I

n November 2009, the U.S. Preventive Services Task Force 1 (USPSTF) issued a statement recommending against routine screening mammography in women aged 40 to 49 years: "The decision to start regular, biennial screening mammography before the age of 50 years should be an individual one and take patient context into account, including the patient's values regarding specific benefits and harms."

This dispassionate declaration, consistent with the evidence at hand, provoked an outcry among patients, politicians, and even some physicians. Many saw the recommendation as a harbinger of health care rationing, whether enforced by the government or opportunistically embraced by the private sector. The force of the backlash caused the Obama administration to backpedal furiously. In an act of political tightrope walking, Secretary of Health and Human Services Kathleen Sebelius left the USPSTF to defend itself. "Mammograms have always been an important lifesaving tool in the fight against breast cancer, and they still are today," she said. "Keep doing what you have been doing for years...."

Whether this is sound medical advice is open to debate, but to watch administration officials sidestep the science and sway to the political winds is, to those who cherish both good science and good government, disheartening. More broadly, the mammography brouhaha bodes poorly for efforts to rationalize the health care system in ways that bend the cost curve downward without hurting quality. Doing so may ultimately require restricting payment for services-including popular but unproven or relatively ineffective preventive services like mammography for young women and prostate screening for older men.

For some, outrage over the USPSTF guideline derived from the perceived threat to consumer choice in health care. The supremacy of choice over other values (such as effectiveness, cost, and safety) united liberal leaning women's health advocates and conservative pundits. They decried the intrusion of government into the physician-patient relationship and argued that the decision of whether or not to order a mammogram should be left to the woman and her doctor. The issue for them is one of choice, not of rational medical decision-making. However, in his book, The Paradox of Choice, Barry Schwartz argues that while Americans now have more choices than ever before, there has not been a coincident increase in our well being. In fact, more choice seems to have led to more anxiety rather than less.

The public health community is not blameless in the November imbroglio. For several decades public health advocates have chanted the mantra of early detection. There is no doubt that early detection of cancer and cardiovascular disease makes sense. But like much else in medicine, what makes sense is not always, uniformly true. With cancer especially, the biology of disease often trumps the chronology. Eventually, new biological insights will permit detection and treatment of disease at crucial points in its evolution. Until then, general internists will play a critical role in interpreting conflicting screening data and recommendations and helping patients to make good decisions. JGIM will support these efforts by continuing to publish original research and perspectives on the reliability, validity, and clinical value of screening-and on explaining the science to patients, and politicians.

Corresponding Author: Richard L. Kravitz, MD, MSPH, UC Davis Division of General Medicine, 4150 V. Street, Suite 2400 PSSB, Sacramento, CA 95817, USA (e-mail: rlkravitz@ucdavis.edu).

Published online January 26, 2010 